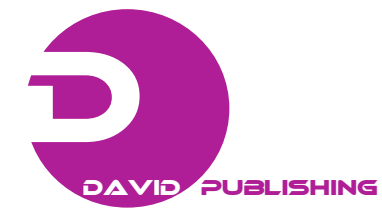

\title{
Investigation into the Total Phenols and Antioxidant Activity during Storage of Fruit Smoothies
}

\author{
Jacob K. Agbenorhevi ${ }^{1}$ and Lisa J. Marshall ${ }^{2}$ \\ 1. Department of Chemical and Biological Sciences, University of Huddersfield, Queensgate, Huddersfield, HD1 3DH, UK \\ 2. School of Food Science and Nutrition, University of Leeds, Leeds, LS2 9JT, UK
}

Received: November 29, 2011 / Published: February 20, 2012.

\begin{abstract}
In this study, the total phenols (TP) and antioxidant activity of three different fruit smoothies (Blackberries, Raspberry and Boysenberry (BRAB), Mango and Passion fruits (MAP) and Blackcurrant, Acerola cherries and Rosehips (BACAR)) were determined during storage by Folin-Ciocalteu and ferric reducing antioxidant power (FRAP) assays respectively. TP ranged from 1,943 to 2,692 $\mathrm{mg} \mathrm{L}^{-1}$ gallic acid equivalent whereas FRAP from 43,217 to $126,125 \mu \mathrm{mol} \mathrm{L}{ }^{-1}$ Trolox equivalent for the three smoothies on opening. BACAR had the highest TP and antioxidant activity. The smoothies showed significant decrease $(P<0.05)$ in TP during storage. The decrease in antioxidant activity was significant $(P<0.05)$ for BRAB and MAP only. However, the study revealed that the smoothies had high antioxidant activity even during shelf-life at $4{ }^{\circ} \mathrm{C}$ which implies that consumption of smoothies may give considerable antioxidant benefits. Correlation between TP and antioxidant activity was strong and highly significant $(r=0.890, P<0.0001)$.
\end{abstract}

Key words: Total phenols, antioxidant activity, fruit smoothies, storage.

\section{Introduction}

The process of oxidation in the human body generates free radicals that can damage membranes and other structures including cellular proteins, lipids and DNA. Dietary antioxidants are substances obtained from the diet which participate in physiological, biochemical and cellular processes. They inactivate free radicals and delay or prevent free radical initiated chemical reactions when present in low concentration with those of an oxidizable substrate [1]. Recently, phenols in foods have gained much attention owing to their antioxidant activity and possible beneficial implications in human health such as prevention of certain cancers and cardiovascular diseases. Many fruit juices contain certain phenolic compounds which possess antioxidant capacity. Phenolics account for the major contribution to antioxidant potential of non-citrus juices while vitamin $\mathrm{C}$ accounts for about $65 \%-100 \%$ of juices derived from citrus fruits $[1,2]$. Other studies had shown that polyphenols account for

Corresponding author: Jacob K. Agbenorhevi, researcher, research field: food chemistry. E-mail: j.agbenorhevi@hud.ac.uk. the majority of antioxidant activity of many fruits when compared to ascorbic acid and other antioxidants $[3,4]$. However, polyphenols can undergo various reactions in the course of food processing and storage. They serve as substrates for the browning enzymes (polyphenol oxidases or phenoloxidases) and enzymes such as esterases, glycosidases and decarboxylases catalyse the transformation and degradation reactions of polyphenolic compounds [5, 6]. Processing and prolong storage can also promote or enhance enzymatic or chemical oxidation of phenolic compounds. Stability of polyphenols is also influenced by $\mathrm{pH}$ [7] and properties of polyphenols are greatly affected by their interaction with the food matrix, such as in the presence of sugars and ascorbic acid $[1,6]$. Phenolics can be affected by storage conditions such as temperature, atmosphere and light. Oxygen has been reported to be an important factor in destabilizing polyphenols, especially anthocyanins, and antioxidant capacity of processed products [8].

A fruit smoothie is described as a $100 \%$ blend of a variety of fruits with no added sugar or additives and 
not made from concentrates. Smoothies are new fruit products of increasing emergence in the market [9]. Smoothies may have increased nutritional and health benefits over fruit juices since they are closer to the whole fruits, thus they contain the flesh, pulp and fibre of the fruits as they are made from the whole (edible) crushed fruits. Smoothies mainly contain highly coloured fruits rich in antioxidants that are linked to providing protection against several diseases. Commonly used fruits include berries which are rich sources of flavonoids (such as anthocyanins, proanthocyanins, flavonols and catechins representing the main subgroups) and phenolic acids as well as antioxidant vitamins. Citrus fruits contain substantial level of flavonone glycosides. Orange juice contains predominantly naringin along with other neohesperidosides. Grapes contain large amount of polyphenols, majority being caftaric acid, tartaric acid ester of caffeic acid, flavan-3-ol catechin and blue-red pigment malvidin-3-glucoside, the major anthocyanin. Apples are also rich sources of phenolic acids and flavonoids. Mango peel and pulp also contain considerable antioxidants and polyphenols such as quercetin, kaempferol, gallic acid, caffeic acid, catechins, tannins and the unique mango xanthone, mangiferin [1, 10-12].

Previous studies on fruits and juices indicated that phenols content may increase [13], decrease [14-16] or remain unchanged $[13,17]$ during storage. Some studies had also shown that vitamin $\mathrm{C}$ in fruits and juices decrease during storage which also influences the antioxidant activities [18-20]. However, the fate of polyphenols and antioxidant activity in smoothies during shelf-life has not been reported.

This study, therefore, aims to investigate the total phenols and antioxidant activity of fruit smoothies during storage.

\section{Materials and Methods}

\subsection{Materials}

Folin-Ciocalteu phenol reagent was purchased from
Fisher Chemicals (Loughborough, UK). 6-hydroxy-2, 5, 7, 8-tetramethyl chroman-2-carboxylic acid (Trolox) was purchased from Acros Organics (Loughborough, UK). Standard gallic acid, standard vitamin C and 2, 4, 6-tri (2-pyridyl)-s-triazine (TPTZ) were obtained from Sigma-Aldrich (Poole, Dorset, UK). All chemicals used were of analytical grade.

Three different types of smoothie drinks namely; Blackberries, Raspberries and Boysenberries (BRAB), Mango and Passion fruit (MAP), and Blackcurrants, Acerola cherries and Rosehips (BACAR) were purchased from Innocent Ltd. (London, UK). Besides the major ingredients representing the bearing name, all the smoothies contained a similar quantity of apple and banana with either orange juice, lemon or lime juice. The ingredients composition of each fruit smoothie is as presented in Table 1. These drinks were selected in order to make comparisons based on their fruit ingredients. To ensure control of age and handling of samples prior to analysis, all smoothie varieties/batches were purchased on the same day when freshly made and the investigations were carried out within their use by/expiry dates.

\subsection{Sample Preparations}

The fruit smoothies were stored at $4{ }^{\circ} \mathrm{C}$ for 4 weeks unopened while some were opened, part sampled and analysed daily for 4 consecutive days. Some drinks were also stored at ambient temperature $\left(21 \pm 1^{\circ} \mathrm{C}\right)$ for two days and sampled for analysis daily. Prior to total phenols and antioxidant activity determinations, each smoothie was diluted 10-fold and then centrifuged (Beckman Model TJ-6 centrifuge) at 2,000 $\times \mathrm{g}$ for 20 $\min$.

\subsection{Determination of Total Phenols}

The total phenol content was analysed using an adapted Folin-Ciocalteu method [2, 21]. $0.1 \mathrm{~mL}$ of sample, standard or blank (distilled water) was pipetted into a $10 \mathrm{~mL}$ volumetric flask and $6.0 \mathrm{~mL}$ of distilled water added. This was followed by adding $0.5 \mathrm{~mL}$ of 
Table 1 Ingredient compositions, vitamin C, mean total phenols content and antioxidant activity of fresh fruit smoothies.

\begin{tabular}{|c|c|c|c|c|}
\hline $\begin{array}{l}\text { Fruit } \\
\text { smoothie }\end{array}$ & Ingredients & Vitamin $\mathrm{C}^{*}\left(\mathrm{mg} \mathrm{L}^{-1}\right)$ & $\begin{array}{l}\left.\text { Total phenols (mg L }{ }^{-1}, \mathrm{GAE}\right) \\
\text { Mean } \pm \text { SD }\end{array}$ & $\begin{array}{l}\text { Antioxidant activity }\left(\mu \mathrm{mol} \mathrm{L}^{-1}, \mathrm{TE}\right) \\
\text { Mean } \pm \mathrm{SD}\end{array}$ \\
\hline BRAB & $\begin{array}{l}47 \text { crushed raspberries }(15 \%) \\
22 \text { crushed boysenberries }(10 \%) \\
20 \text { crushed blackberries }(8 \%) \\
8 \text { pressed apples } \\
2 \text { mashed bananas } \\
17 \text { pressed white grapes } \\
1 \text { orange and a dash of lemon juice }\end{array}$ & 100 & $2,040.0 \pm 23.6^{\mathrm{a}}$ & $75,792 \pm 3,359^{\mathrm{a}}$ \\
\hline MAP & $\begin{array}{l}21 / 2 \text { crushed Mangoes }(23 \%) \\
2 \text { crushed passion fruits }(5 \%) \\
11 \text { pressed apples } \\
11 / 2 \text { mashed banana } \\
2 \text { freshly squeezed oranges } \\
\text { a squeeze of lemon }\end{array}$ & 240 & $1,943.3 \pm 70.7^{\mathrm{a}}$ & $43,217 \pm 1,225^{b}$ \\
\hline BACAR & $\begin{array}{l}450 \text { blackcurrants }(14 \%) \\
28 \text { acerola cherries }(11 \%) \\
6 \text { rosehips }(2 \%) \\
9 \text { pressed apples } \\
3 \text { mashed bananas } \\
1 \text { freshly squeezed orange }\end{array}$ & 910 & $2,692 \pm 21.6^{b}$ & $126,125 \pm 2,887^{\mathrm{c}}$ \\
\hline
\end{tabular}

Folin-Ciocalteu reagent $(2 \mathrm{~N})$. The solution was thoroughly mixed and left to stand for $5 \mathrm{~min}$ at ambient temperature. $1.5 \mathrm{~mL}$ of $20 \% \mathrm{Na}_{2} \mathrm{CO}_{3}$ solution was added and the solution was made up to the $10 \mathrm{~mL}$ mark with distilled water and mixed thoroughly. The resulting solution was then incubated at ambient temperature for 2 $\mathrm{h}$ in the absence of light after which absorbance readings were taken at $765 \mathrm{~nm}$ using a spectrophotometer (Shimazu UV-VIS 160A). All measurements were performed at least in triplicate on six different cartons of each smoothie. A calibration curve was constructed using standard gallic acid and the results expressed as gallic acid equivalent (GAE, $\mathrm{mg} \mathrm{L}^{-1}$ ).

\subsection{Determination of Antioxidant Activity}

The antioxidant activity was determined by using the ferric reducing antioxidant power (FRAP) assay [2, 22, 23]. The FRAP reagent was prepared by mixing 200 $\mathrm{mL}$ of $300 \mathrm{mM}$ acetate buffer, $20 \mathrm{~mL}$ of $10 \mathrm{mM}$ TPTZ solution, $20 \mathrm{~mL}$ of $20 \mathrm{mM} \mathrm{FeCl}_{3}$ solution and $24 \mathrm{~mL}$ distilled water. The FRAP reagent, TPTZ and $\mathrm{FeCl}_{3}$ solutions were freshly prepared on each day of assay. A $0.2 \mathrm{~mL}$ of sample extract (diluted by $10 \%$ ), standard or blank (distilled water) was pipetted into a test tube and $6.0 \mathrm{~mL}$ of FRAP reagent added. It was mixed and the absorbance was read with a spectrophotometer (Shimazu UV-VIS 160A) at $593 \mathrm{~nm}$ after $10 \mathrm{~min}$. All measurements were performed at least in triplicate on six different cartons of each smoothie. A calibration curve was constructed using standard Trolox and the results expressed as micromol Trolox equivalent (TE, $\left.\mu \mathrm{mol} \mathrm{L}{ }^{-1}\right)$.

\section{5 pH Measurement}

In order to assess for any changes during storage and correlation with the antioxidant properties, the $\mathrm{pH}$ of all smoothies (both fresh and stored) was also measured using a Jenway 3305 pH meter.

\subsection{Statistical Analysis}

The results obtained were analysed statistically using SPSS version 12 (SPSS Inc., IL, USA). The mean total phenol content and antioxidant activity of smoothies at different storage times and conditions were compared using one-way ANOVA followed by LSD post hoc multiple comparisons. 


\section{Results and Discussion}

\subsection{Total Phenols Content and Antioxidant Activity of Fresh Smoothie Drinks}

The total phenols (TP) and antioxidant activity of three different types of fruit smoothie were determined. BACAR smoothie had the highest TP, followed by BRAB smoothie and MAP smoothie (Table 1). The differences in TP could be attributed to the different fruit ingredients. Berries are known to have high levels of phenols; however, sour cherries in BACAR contain relatively higher TP as compared to berries [24]. Therefore, blackcurrants and cherries as well as the percentage composition of other fruits (apples, bananas, orange juice) could possibly account for the relatively high TP content of BACAR compared to MAP and BRAB drinks. Results showed that smoothies have a higher TP in comparison to some fruit juices reported previously. Piljac-Žegorac and others [25] monitored six industrial dark fruit juices and found that blackcurrant juice had the highest TP content $(1,920$ $\mathrm{mg} \mathrm{L}^{-1} \mathrm{GAE}$ ). Comparatively, smoothies had higher TP than that of various fruit juices reported by Gardner and others [2] with orange juice having the highest TP content at $755 \mathrm{mg} \mathrm{L}^{-1} \mathrm{GAE}$. The higher TP content of the smoothies compared to these juices could be due to significant contribution from their various fruit ingredients. Furthermore, unlike juices, smoothies contain the pulp and the skins of some fruits thereby enriching the polyphenols content [24]. Vitamin C content was the highest in BACAR, followed by MAP and BRAB (Table 1). As with TP, BACAR had the highest antioxidant activity, followed by BRAB and lastly MAP (Table 1). However, MAP had higher vitamin $C$ than BRAB but antioxidant activity of MAP was significantly lower than that of BRAB. This suggests that TP contributes largely to the antioxidant activity of smoothies in comparison to vitamin $\mathrm{C}$. These findings are in agreement with previous reports that showed polyphenols account for the majority of antioxidant activity of many fruits when compared to ascorbic acid and other antioxidants [3, 4, 14]. It has also been reported that phenolics have a major contribution to antioxidant potential of non-citrus juices while vitamin $\mathrm{C}$ was found to account for about 65\%-100\% of juices derived from citrus fruits [2]. Correlation between TP and antioxidant activity of smoothies was found to be highly significant $(r=0.890$, $P<0.0001$ ), which is in agreement with other findings $[2,14,26,27]$.

\subsection{Total Phenols and Antioxidant Activity during Storage at $4{ }^{\circ} \mathrm{C}$}

Smoothies were stored unopened at $4{ }^{\circ} \mathrm{C}$ for 4 weeks and a general significant decrease was observed in TP (Fig. 1).

A possible reason for the observed decrease in TP during storage could be due to the polyphenols reacting with sugars and sugar metabolites present in the smoothies. For instance, stability of anthocyanins is known to decrease as sugar content increases [28]. At the end of the 4 weeks storage period, BACAR still had the highest TP content (2,173 $\left.\mathrm{mg} \mathrm{L}^{-1} \mathrm{GAE}\right)$, followed by BRAB (1265 mg L $\left.\mathrm{m}^{-1} \mathrm{GAE}\right)$ and lastly MAP (936 $\mathrm{mg} \mathrm{L}^{-1}$ GAE). MAP experienced more average loss in TP (46\%-60\%) than that of BRAB (28\%-38\%) and BACAR (14\%-20\%) after the first to fourth week of storage unopened. The variation in decreasing rate could be dependent on the type of polyphenols and their stability.

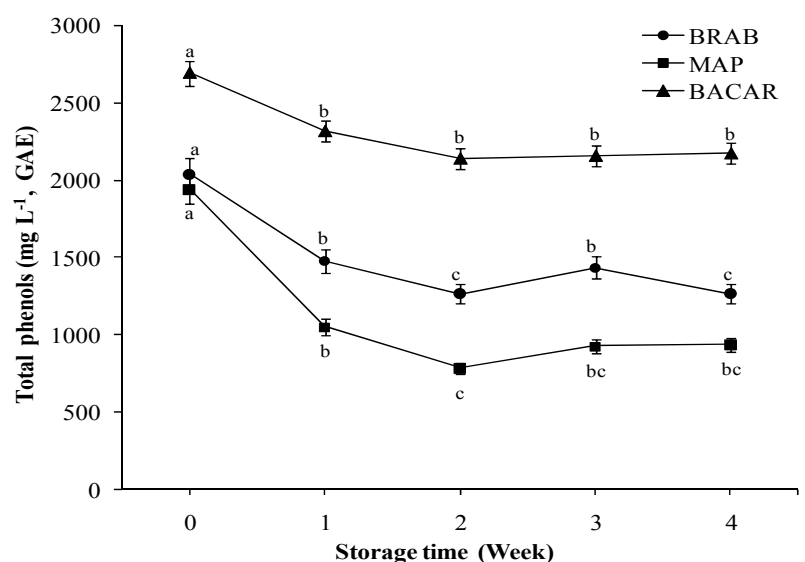

Fig. 1 Total phenol content of fruit smoothies during storage at $4{ }^{\circ} \mathrm{C}$. GAE: Gallic acid equivalent. ${ }^{\text {a-c }}$ Treatments on the same line (same smoothie) with different letters are significantly different $(P<0.05)$. 
The $\mathrm{pH}$ of the smoothies could be another possible factor. The $\mathrm{pH}$ is thought to contribute significantly to the oxidative stability of total phenols, vitamin $\mathrm{C}$ and thus antioxidant activity of smoothies because low $\mathrm{pH}$ helps to inhibit microbial growth and some enzymatic reactions. The stability of polyphenols (particularly anthocyanins) is high at low $\mathrm{pH}$ [7]. Vitamin $\mathrm{C}$ is also stable at low $\mathrm{pH}$ and destroyed by increased $\mathrm{pH}$ [29]. Even though the $\mathrm{pH}$ of the smoothies was quite low (data not shown due to no significant variations; 3.2-3.4, 3.1-3.3 and 3.1-3.2 for MAP, BRAP and BACAR respectively) for both fresh and stored samples, stability of polyphenols was still affected. It was found that TP and antioxidant activity correlate significantly with $\mathrm{pH}$ in an inverse relationship ( $r=-0.519$ and -0.534 respectively). However, $\mathrm{pH}$ of the smoothies was relatively stable after the first two weeks to the fourth week with that of BACAR being most stable.

In general, antioxidant activity of smoothies decreased during storage (Fig. 2) and the decrease could be attributed to the loss of TP. After one week of cold storage at $4{ }^{\circ} \mathrm{C}$, the antioxidant activity of BRAB, MAP and BACAR were $87 \%, 82 \%$ and $91 \%$ respectively in comparison to their respective fresh samples. At the end of the fourth week of storage, MAP had approximately $77 \%$, BRAB $82 \%$ and BACAR $93 \%$ antioxidant activity in comparison to the respective fresh samples. The decrease in antioxidant capacity for BACAR from fresh to week four was not significant while that of BRAB and MAP were significant $(P<0.05$, Fig. 2$)$. This may be due to the relatively high content and/or stability of vitamin $\mathrm{C}$ and polyphenols in BACAR, thereby maintaining its antioxidant activity.

Miller and Rice-Evans [30] suggested that the phenolic antioxidants protect vitamin $\mathrm{C}$ against oxidative decomposition with those in blackcurrants having the greatest vitamin $\mathrm{C}$ sparing activity than oranges and apples. Polyphenols may protect vitamin C by donating hydrogen to convert dehydroascorbic acid back to ascorbic acid in redox reactions.

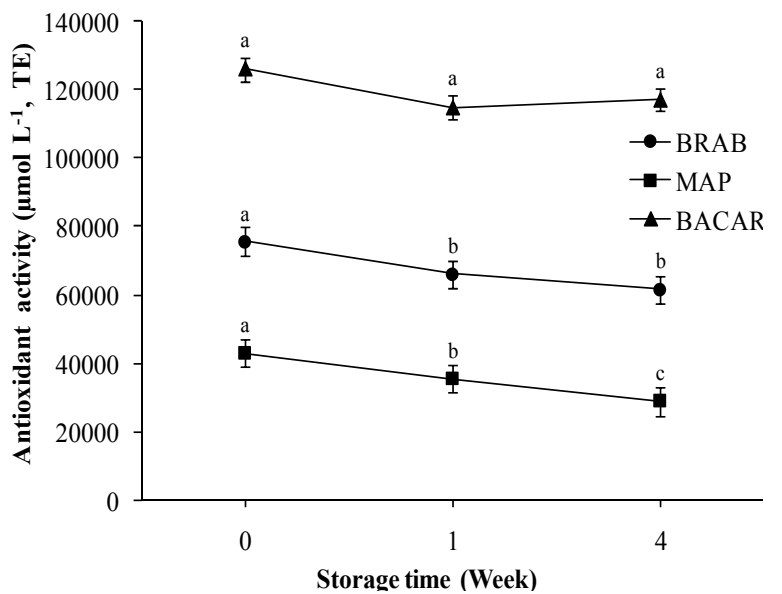

Fig. 2 Antioxidant activity of smoothies during storage at $4{ }^{\circ} \mathrm{C}$. TE: Trolox equivalent. ${ }^{\text {a-c }}$ Treatments on the same line with different letters are significantly different $(P<0.05)$.

There was a significant loss $(P<0.05)$ in TP and antioxidant activity over four days when smoothies were opened, part taken out and the remaining put back in the refrigerator (Fig. 3). This is as a result of oxygen entry into the container each time the carton was opened and consequently causing degradation of polyphenols and vitamin C [29]. The decrease continued with storage time possibly because of more oxygen entering into the container during re-opening. The variation in decrease may also depend on the volume of oxygen that entered the container. A similar effect has been observed where oxygen availability rate accounted for the highest effect on lowering antioxidant activity during pasteurization and storage of black chokeberry juice [15].

Introduction of oxygen when blueberry juice samples were shaken has also been reported to cause a significant negative effect on monomeric anthocyanins, total phenolics and antioxidant capacity [8]. From these observations, it is therefore important that once the smoothie is opened, it should be consumed within the stated four days and should be quickly closed to minimize oxygen entry if not all will be consumed.

\subsection{Total Phenols and Antioxidant Activity during Storage at Ambient Temperature}

Smoothies stored at ambient temperature $\left(21 \pm 1^{\circ} \mathrm{C}\right)$ experienced loss in TP (Fig. 4a). A similar observation 


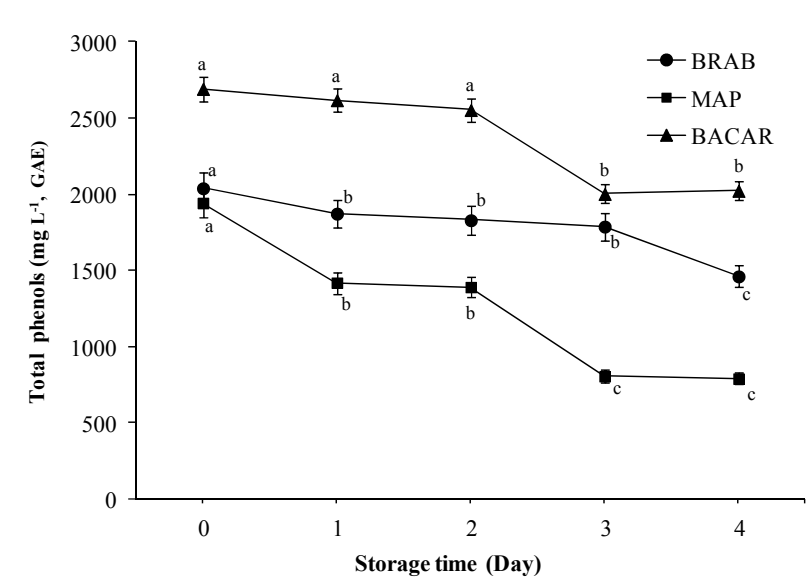

(a)

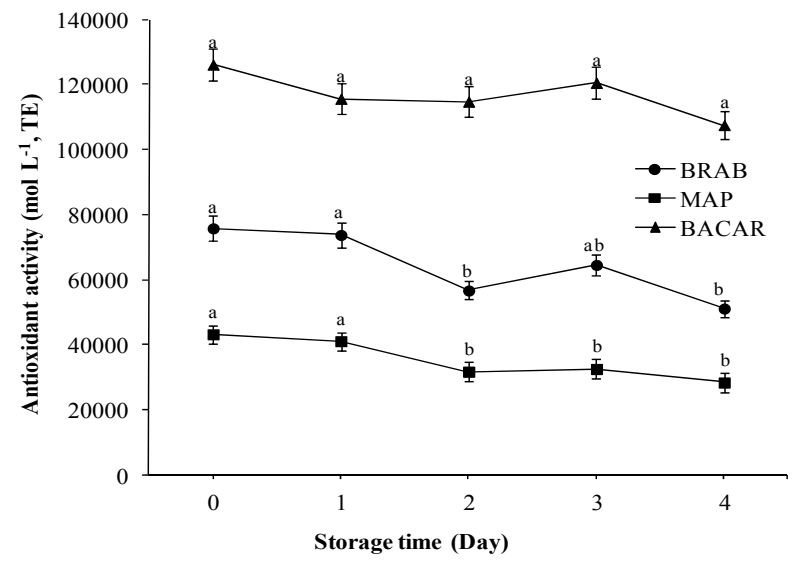

(b)

Fig. 3 (a) Total phenols and (b) antioxidant activity of smoothies when opened and refrigerated (at $4{ }^{\circ} \mathrm{C}$ ) over four days. ${ }^{\text {a-c }}$ Treatments on the same line with different letters are significantly different $(P<0.05)$.

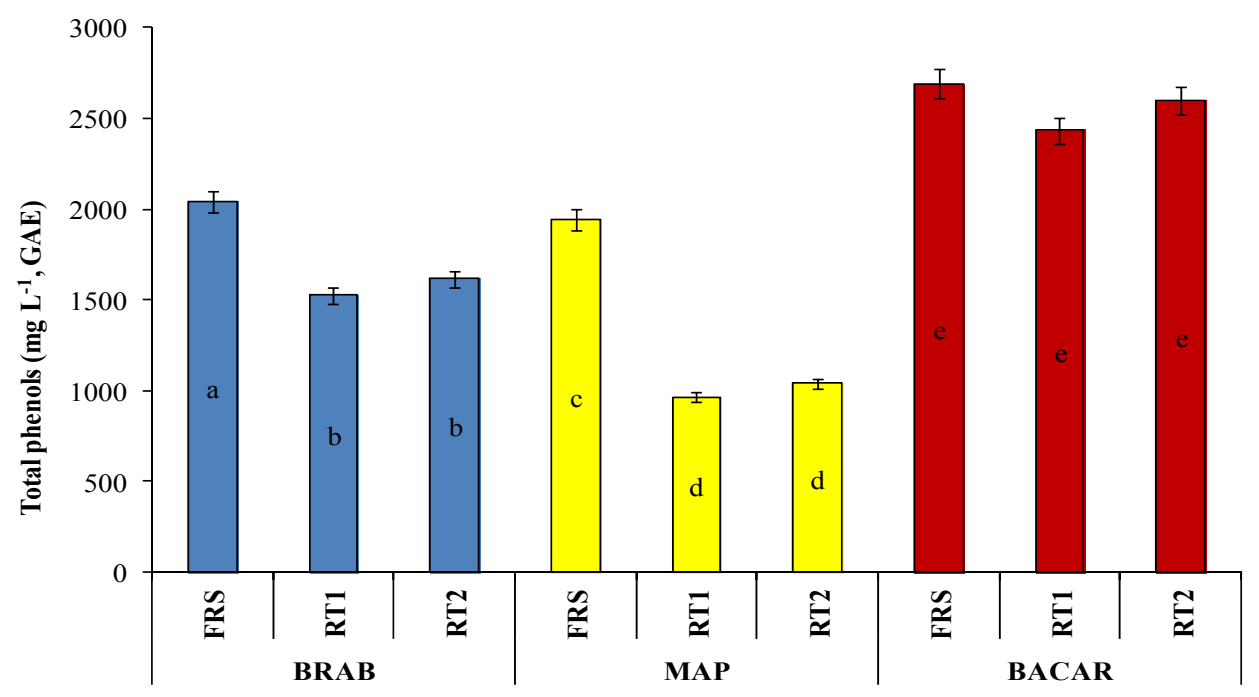

(a)

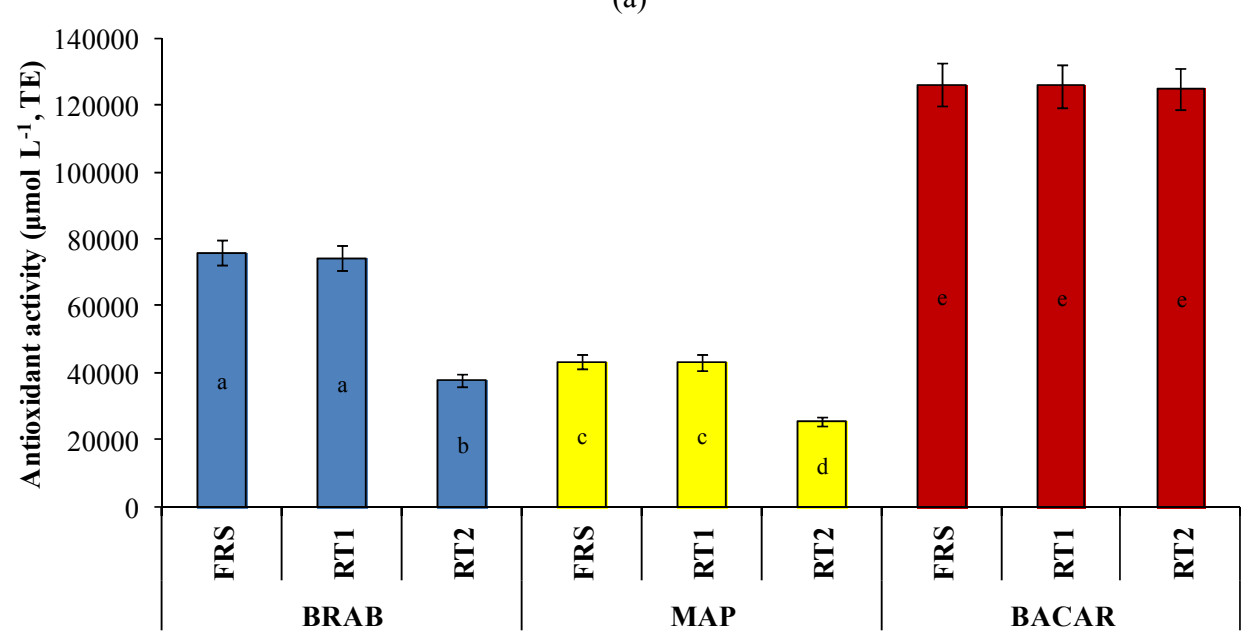

(b)

Fig. 4 (a) Total phenols and (b) antioxidant activity of smoothies at ambient temperature $\left(21 \pm 1^{\circ} \mathrm{C}\right)$. GAE: Gallic acid equivalent; TE: Trolox equivalent. FRS: Fresh (Control) sample; RT1: Room Temperature Day 1; RT2: Room Temperature Day 2. ${ }^{\text {a-e }}$ Treatments/Bars of the same colour (same smoothie) with different letters are significantly different $(P<0.05)$. 
has been previously reported for apple juices [14]. BRAB had approximately $25 \%$ loss in TP, MAP $50 \%$ loss and BACAR had $10 \%$ loss when kept at ambient temperature over $24 \mathrm{~h}$. The TP loss in BACAR was not significant but those of BRAB and MAP were significant $(P<0.05)$. The polyphenols in BACAR might be more stable or less susceptible to degradation at ambient temperature than those in BRAB and MAP. Similarly, the antioxidant activity of smoothies also decreased slightly when stored at ambient temperature (Fig. 4b). The decrease in antioxidant activity was not significant after the first day but highly significant after the second day for MAP and BRAB. Antioxidant activity of BACAR was almost the same even after the second day. Like MAP and $\mathrm{BRAB}$, and unlike BACAR, antioxidants in noni juice have been reported to be unstable when stored at $24{ }^{\circ} \mathrm{C}$ [16]. Formation of slight colour changes and bubbling due to fermentation were observed in each smoothie by the first $24 \mathrm{~h}$ of storage at ambient temperature and this could be attributed to the observed decline in antioxidant properties especially for MAP and BRAB. Therefore it is important to avoid leaving the smoothies at ambient temperature so as to maintain the beneficial qualities.

\section{Conclusion}

In this investigation, different types of fruit smoothies were found to have different total phenols content and antioxidant activities, attributable to their respective fruit ingredients. There was a significant loss $(P<0.05)$ in TP and antioxidant activity over 4 days storage at $4{ }^{\circ} \mathrm{C}$ when smoothies were opened, part taken out and the remaining put back in the refrigerator. This is as a result of oxygen entry into the container which causes degradation of polyphenols and vitamin $\mathrm{C}$. When smoothies were stored at ambient temperature the losses in TP, and antioxidant activity were variable. During unopened storage of the smoothies at $4{ }^{\circ} \mathrm{C}$ for 4 weeks, all smoothies experienced a significant decrease $(P<$
$0.05)$ in TP. The decrease in antioxidant activity for BACAR was not significant while that of BRAB and MAP were significant. This study revealed that the smoothies used had high TP and antioxidant activity even after the four weeks shelf-life at $4{ }^{\circ} \mathrm{C}$ which implies that consumption of smoothies may give considerable antioxidant benefits.

\section{References}

[1] C. Kaur, H.C. Kapoor, Antioxidants in fruits and vegetables-the millenium's health, Int. J. Food Sci. Technol. 36 (2001) 703-725.

[2] P.T. Gardner, T.A.C. White, D.B. McPhail, G.G. Duthie, The relative contributions of vitamin $\mathrm{C}$, carotenoids and phenolics to the antioxidant potential of fruit juices, Food Chem. 68 (2000) 471-474.

[3] H. Wang, G. Cao, R.L. Prior, Total antioxidant capacity of fruits, J. Agric. Food Chem. 44 (1996) 701-705.

[4] N. Deighton, R. Brennan, C. Finn, H.V. Davies, Antioxidant properties of domesticated and wild Rubus species, J. Sci. Food Agric. 80 (2000) 1307-1313.

[5] G. Skrede, R.E. Wrolstad, R.W. Durst, Changes in anthocyanins and polyphenolics during juice processing of highbush blueberries (Vaccinium corymbosum L.), J. Food Sci. 65 (2000) 357-364.

[6] V. Cheynier, Polyphenols in foods are more complex than often thought, Am. J. Clin. Nutr. 81 (2005) 223-229.

[7] W. Kalt, Effects of production and processing factors on major fruits and vegetable antioxidants, J. Food Sci. 70 (2005) 11-19.

[8] W. Kalt, J.E. McDonald, H. Donner, Anthocyanins, phenolics, and antioxidant capacity of processed lowbush blueberry products, J. Food Sci. 65 (2000) 390-393.

[9] G. Hunt, Nature vs. nurture, Food Manufacture 81 (2006) 45-46.

[10] K. Mahattanawee, J.A. Manthey, G. Luzio, S.T. Talcott, K. Goodner, E.A. Baldwin, Total antioxidant activity and fiber content of selected Florida grown mango cultivars, J. Agric. Food Chem. 54 (2006) 7355-7366.

[11] M. D'Archivio, C. Filesi, R.D. Benedetto, R. Garginlo, C. Giovannini, R. Masella, Polyphenols, dietary sources and bioavailability, Ann $1^{\text {st }}$ Super Sanita 43 (2007) 348-361.

[12] X. Han, T. Shen, H. Lon, Dietary polyphenols and their biological significance, Int. J. Mol. Sci. 8 (2007) 950-988.

[13] W. Kalt, C.F. Forney, A. Martin, R.L. Prior, Antioxidant capacity, vitamin C, phenolics, and anthocyanins after fresh storage of small fruits, J. Agric. Food Chem. 47 (1999) 4638-4644.

[14] A. Gliszczynska-Swiglo, B. Tyrakowska, Quality of 
commercial apple juices evaluated on the basis of the polyphenol content and the TEAC antioxidant activity, J. Food Sci. 68 (2003) 1844-1849.

[15] D. Walkowiak-Tomczak, Changes in antioxidant activity of black chokeberry juice concentrate solutions during storage, ACTA Scientiarum Polonorum. 6 (2007) 49-55.

[16] J. Yang, R. Paulino, S. Janke-Stedronsky, F. Abawi, Free-radical-scavenging activity and total phenols of noni (Morinda citrifolia L.) juice and powder in processing and storage, Food Chem. 102 (2007) 302-308.

[17] W. Mullen, A.J. Stewart, M.E.J. Lean, P. Gardner, G.G. Duthie, A. Crozier, Effect of freezing and storage on the phenolics, ellagitannins, flavonoids and antioxidant capacity of red raspberries, J. Agric. Food Chem. 50 (2002) 5197-5201.

[18] B. De Ancos, E.M. González, M.P. Cano, Ellagic acid, vitamin $\mathrm{C}$ and total phenolic contents and radical scavenging capacity affected by freezing and frozen storage in raspberry fruit, J. Agric. Food Chem. 48 (2000) 4565-4570.

[19] K. Zerdin, M.L. Rooney, J. Vermuë, The vitamin C content of orange juice packed in an oxygen scavenger material, Food Chem. 82 (2003) 387-395.

[20] I. Klimczak, M. Malecka, M. Szlachta, A. Gliszczyńska-Świglo, Effect of storage on the content of polyphenols, vitamin $\mathrm{C}$ and the antioxidant activity of orange juices, J. Food Compos. Anal. 20 (2006) 313-322.

[21] K. Slinkard, V.L. Singleton, Total phenol analysis: Automation and comparison with manual methods, AJEV.
28 (1977) 49-55.

[22] I.F.F. Benzie, J.J. Strain, The ferric reducing ability of plasma (FRAP) as a measure of "antioxidant power": The FRAP assay, Anal. Biochem. 239 (1996) 70-76.

[23] A. Wojdylo, J. Oszmiański, R. Czemerys, Antioxidant activity and phenolic compounds in 32 selected herbs, Food Chem. 105 (2007) 940-949.

[24] D. Marinova, F. Ribarova, M. Atanassova, Total phenolics and total flavonoids in Bulgarian fruits and vegetables, J. UCTM. 40 (2005) 255-260.

[25] L. Piljac-Žegorac, L. Valek, S. Martinez, A. Belščak, Fluctuations in the phenolic content and antioxidant capacity of dark fruit juices in refrigerated storage, Food Chem. 113 (2009) 394-400.

[26] C. Kaur, H.C. Kapoor, Anti-oxidant activity and total phenolic content of some Asian vegetables, Int. J. Food Sci. Technol. 37 (2002) 153-161.

[27] Y. Yao, W. Sang, M. Zhou, G. Ren, Phenolic composition and antioxidant activities of 11 celery cultivars, J. Food Sci. 75 (2010) 9-13.

[28] B.R. Thakur, S.S. Arya, Studies on stability of blue grape anthocyanins, Int. J. Food Sci. Technol. 24 (2007) 321-326.

[29] T.P. Coultate, Food: The Chemistry of Its Components, Royal Society of Chemistry, Cambridge, UK, 2002, pp. 281-288.

[30] N.J. Miller, C.A. Rice-Evans, The relative contributions of ascorbic acid and phenolic antioxidants to the total antioxidant activity of orange and apple fruit juices and blackcurrant drink, Food Chem. 60 (1997) 331-337. 